\title{
Rapidly changing life history during invasion
}

Thomas Bøhn ${ }^{1,2}$, Odd Terje Sandlund ${ }^{3}$, Per-Arne Amundsen ${ }^{2} \&$ Raul Primicerio $^{2}$

${ }^{1}$ Norwegian Institute of Gene Ecology, The Science Park, P.O. box 6418, N-9294,

Norway. Phone corresponding author: +47 77644541, Fax: +47 77646100, email:

thomas@genok.org

${ }^{2}$ Norwegian College of Fisheries Science, University of Tromsø, NO-9037 Tromsø,

Norway.

${ }^{3}$ Norwegian Institute for Nature Research, Tungasletta 2, NO-7485 Trondheim, Norway

Keywords: boom and bust, density dependence, invasion, life history strategy, pioneer population, phenotypic plasiticity, reaction norm, trade-off. 


\begin{abstract}
The fish species Vendace (Coregonus albula) invaded the subarctic Pasvik watercourse during the second half of the 1980s, and became the dominant pelagic species in the upstream part of the watercourse within a few years. Life history traits of the pioneer population of vendace in Pasvik were recorded from 1991-2000. A rapid increase in population density in the upstream part of the watercourse was accompanied by decreased growth rates, decreased fecundity and a reduced size at first maturation. The downstream part of the watercourse showed a similar, but delayed, change in life history traits compared to the upstream part. The study documents great life history variability of a non-native fish species entering a new environment. We discuss two co-acting explanations for the observed patterns: (i) a density dependent response mediated by food depletion; and (ii) a pioneer strategy that allocates resources to favour reproduction at early developmental stages with a high number of offspring, trading off growth and size of offspring.
\end{abstract}




\section{Introduction}

Introductions and establishment of non-native (or 'alien') invasive species is one of the major threats to native biodiversity on a global scale (Diamond 1985, Glowka et al. 1994, Williamson 1996). Freshwater ecosystems are among the most susceptible to invading species (Mills et al. 1993, Cohen and Carlton 1998), and the rate of introductions is continually increasing due to both intentional and accidental introductions of non-native species (Welcomme 1992, Moyle 1999). In spite of the recent emphasis on introductions, several aspects of invasions and species establishment are poorly understood. For example, the population dynamics of the introduced species during establishment have rarely been documented (Williamson 1999), particularly not in long time series.

Explanations of success and failure seem to require considerable detail on each invasion case (Williamson 1996, 1999), details that are often missing since most invasions are studied (a long time) after establishment. Improved understanding of the characteristics of successful invaders is necessary in order to improve our ability to counteract both invasions, and their negative impacts on ecosystems (Mooney and Hobbs 2000).

This paper documents the demography of the freshwater fish species vendace (Coregonus albula) during its development over a decade, from first occurrence to an established population, in the Pasvik watercourse. The vendace population has expanded extensively downstream during the 1990s and has proven to be a dominant species in the upstream part of the watercourse. As predator it has grazed down the zooplankton, strongly reducing the edible food resources in the pelagic habitat (Bøhn and Amundsen 1998, 2001). As the superior pelagic competitor it has excluded the native whitefish (Coregonus 
lavaretus) from the pelagic food and habitat niche (Amundsen et al. 1999, Bøhn and Amundsen 2001). And, as a small sized fish with very high density, the vendace has become the most frequent prey of pelagic piscivorous fish (Bøhn et al. 2002). In the downstream part of the watercourse, the establishment of vendace is delayed and the present situation resembles early stages of the process in the upstream part. The development of the vendace population has been followed from 1991 to 2000 .

The life history of an invading species is interesting for several reasons: firstly, the invading pioneer population is often small and may display a deviant life history as compared to well-established conspecific populations. Secondly, through the process of invasion and establishment a species may be studied both under density-independent and density dependent conditions in a large scale 'natural experiment', allowing comparative statistical tests and application of ecological theory. In early stages the density is low and no intraspecific competition can be expected, later the gradually increasing density is expected to intensify intraspecific competition, resulting in a density dependent reaction norm of life history traits. Thirdly, the invader's flexibility in coping with changing (internal and external) conditions during the establishment phase may determine its success as an invader (cf. Rosecchi et al. 2001). Changes in life history traits are particularly relevant in studies of fish since this taxon has indeterminate growth (Roff 1984, 2002, Stearns and Koella 1986, Wootton 1998) and may show great plasticity in growth and fecundity. Plastic responses and selection on relevant traits may quickly modify phenotypes in periods of rapid population growth (Reznick et al. 1997, Hendry et al. 2000). Fourthly, long time series covering the complete invasion and establishment 
process may be used to estimate the time needed before the invader's plastic life history stabilises in the new environment. Finally, life history studies, integrated with population and community analysis, help to understand which are invasive skills of non-native species and what is the ability of receiving communities, including humans, to respond to artificially high rates of species transfer (e.g. Mooney and Hobbs 2000).

Based on life history theory (Roff 1992, Stearns 1992, Charlesworth 1994) we formulate a set of hypotheses regarding the expected changes in life history traits of vendace associated with changes in density during immigration and establishment in the new environment: during early stages of establishment (low density, low intraspecific competition and relatively abundant food resources), we expected a life history characterised by: (A1) high individual growth rates, (A2) high relative reproductive investment, (A3) early maturation, and (A4) small size of eggs, egg size being traded off for high egg numbers.

During later stages of the invasion (higher density, higher competition and relatively scarce food resources), the life history is expected to change to: (B1) lower individual growth rates, (B2) lower relative reproductive investment, (B3) later maturation, and (B4) low fecundity, egg numbers being traded off for larger egg sizes, which favours offspring survival under low food availability.

\section{Study area and fish community}

Three countries share the Pasvik River watercourse. It originates in Lake Inari $\left(1102 \mathrm{~km}^{2}\right)$ in Finland, runs into Russia and then forms the border between Norway and Russia over a distance of about $120 \mathrm{~km}$ (Fig. 1). The Norwegian-Russian part of the river system has a 
total area of $142 \mathrm{~km}^{2}$, a catchment area of $18404 \mathrm{~km}^{2}$ and a mean annual water flow of about $175 \mathrm{~m}^{3} \mathrm{~s}^{-1}$. There are a total of seven water impoundments (hydropower reservoirs) in this part of the watercourse. Most rapids and waterfalls have disappeared so that the river system today consists primarily of lakes and reservoirs linked by slow-flowing river sections. The bedrock in the region is dominated by gneiss, and surrounding forest is mainly birch (Betula sp.) and pine (Pinus sylvestris) with significant areas of Sphagnum bogs. Annual mean air temperature is $-3{ }^{\circ} \mathrm{C}$ and minimum and maximum monthly mean temperatures are $-13.5{ }^{\circ} \mathrm{C}$ (January) and $+14.0{ }^{\circ} \mathrm{C}$ (July), respectively. The annual mean precipitation is $358 \mathrm{~mm}$. The water level fluctuations are small, usually less than $80 \mathrm{~cm}$. The ice-free season in the lakes and reservoirs lasts from May - June to October November. The lakes and reservoirs are oligotrophic with relatively humic waters. The Secchi-depth ranges from 2 to $6 \mathrm{~m}$.

Two different lake localities, situated about $50 \mathrm{~km}$ apart in the watercourse, were investigated: Ruskebukta in the upstream part (called the upstream lake in the following), and Skrukkebukta downstream (downstream lake) (Fig. 1). Both basins are located adjacent to the main path of the Pasvik watercourse, and have negligible water flow. The upstream lake $\left(69^{\circ} 13^{\prime} \mathrm{N}, 29^{\circ} 14^{\prime} \mathrm{E} ; 52 \mathrm{~m}\right.$ above sea level) has an area of $5.3 \mathrm{~km}^{2}$, whereas the downstream lake $\left(69^{\circ} 33^{\prime} \mathrm{N}, 30^{\circ} 7^{\prime} \mathrm{E} ; 21 \mathrm{~m}\right.$ above sea level) has an area of $6.6 \mathrm{~km}^{2}$. The water chemistry of the two lakes is very similar (Langeland 1993).

Altogether, 15 species of fish have been recorded in the Pasvik watercourse. The two lake localities have similar fish communities, with whitefish (Coregonus lavaretus (L). sensu lato), perch (Perca fluviatilis L.), pike (Esox lucius L.), burbot (Lota lota L.) and brown trout (Salmo trutta L.) being the most abundant native species. The whitefish 
occur as two different morphs, differentiated both by morphology (number of gill rakers) and ecology (food and habitat selection) (Amundsen et al. 1999).

The natural distribution of vendace in Scandinavia and Finland is restricted to the low altitude watercourses which at present or previously drained into the Baltic Sea (Svärdson 1966, Rask et al. 2000). Due to its postglacial immigration history, the species was originally absent from freshwater systems in the northern and western parts of this region. However, during the 1950s and 1960s, vendace was introduced into the catchment area of Lake Inari in northern Finland (Mutenia and Salonen 1992). It was first observed in Lake Inari in 1973, and a dense population developed during the late 1980s (Mutenia and Salonen 1994). Lake Inari drains into the Pasvik River, and the first specimens of vendace were caught in the upstream part of the river system in 1989. In the downstream part of the Pasvik system, the first vendace were caught in 1993 (Bøhn and Amundsen 1998).

\section{Methods and material}

Sampling was performed during the ice-free season from 1991 to 2000. Within a season sampling took place in June/July, August and September 1991, 1993, 1998 and 2000, in July and September 1992, in September 1995 and 1997, and in October 1999. Gill nets with mesh sizes of $8,10,12.5,15,18.5,22,26,35$ and $45 \mathrm{~mm}$ (knot to knot) were used in the pelagic habitat. Pelagic gill nets consisted of two different types: $40 \mathrm{~m}$ long and $4 \mathrm{~m}$ deep; and $16 \mathrm{~m}$ long and $12 \mathrm{~m}$ deep. Additional benthic gill nets, $1.5 \mathrm{~m}$ deep, were used in the profundal and littoral. The total sample of vendace consisted of 2648 fish (Table 1), of which 9.9 percent were caught in the littoral and profundal habitats. In the following, 
only the pelagic catches are included in the analysis. The catch per unit effort (CPUE number of fish per $100 \mathrm{~m}^{2}$ per 12 hours) of vendace was calculated from the September and October samples only, due to large seasonal variation. CPUE is used as an indicator of fish density in the pelagic zone. A similar indicator for pelagic fish biomass was obtained by multiplying CPUE with the mean weight of the fish.

All fish were measured in mm (fork length) and weighed in grams. The sex and stage of maturity were determined, and a sub-sample of female gonads was weighed in milligrams. The age of the fish was determined by counting the number of winter zones on the otoliths (Skurdal et al. 1985).

In order to compare the asymptotic length and individual growth rate for vendace between years and localities, a non-linear approximation of a modified von Bertalanffy growth model was applied:

$L(\mathrm{t})=L(\infty)-(L(\infty)-L(\mathrm{t}-1)) * \mathrm{e}^{\left(-K^{*} L(\mathrm{t})\right)}(($ Forseth et al. 1997));

where $L(\mathrm{t})=$ mean length of fish at age $\mathrm{t}, L(\mathrm{t}-1)=$ length the previous year, $L(\infty)=$ asymptotic length, and $K=$ growth rate to asymptote. Calculations were performed with the Systat 10.0 software, based on mean lengths of each year-class from all the years of study. A hatching length of $11 \mathrm{~mm}$ was set based on literature data (Næsje et al. 1986b, Næsje et al. 1986a).

As calculated here, the asymptotic length describes the theoretical maximum fish length in the vendace population within each locality and within each year of study. 
The gonadosomatic index (GSI), which estimates gonad weight relative to somatic body weight in percent, is used as an indicator of reproductive investment in individual female fish (Mills and Eloranta 1985). GSI was calculated according to:

$G S I=100\left(W_{\mathrm{g}} /\left(W_{\mathrm{t}}-W_{\mathrm{g}}\right)\right)$

where $W_{\mathrm{g}}$ is the gonad weight and $W_{\mathrm{t}}$ is the total weight of the fish.

The individual fecundity was calculated after weighing 50 eggs and then the total gonads. As a test of measurement precision, three parallel samples from 14 different fish were compared. Mean and maximum discrepancies from the average value were 6.4 and 11.8 $\%$, respectively.

A General Linear Model (GLM) was applied to the fecundity data using ln (egg numbers) $\left(E g g_{\#}\right)$ as the dependent variable and $\ln ($ egg size $)\left(E g g_{\text {size }}\right), \ln ($ fish weight $)\left(\right.$ Weight $\left._{\text {fish }}\right)$, fish density (Density fish $_{\text {, }}$, year and locality as independent variables. The full model can be written as an equation of the form:

$E g g_{\#}=\mathrm{a} \cdot \operatorname{Egg}_{\mathrm{size}}+\mathrm{b} \cdot$ Weight $_{\mathrm{fish}}+\mathrm{c} \cdot$ Density $_{\mathrm{fish}}+\mathrm{d} \cdot$ Year $+\mathrm{e} \cdot$ Locality $_{\text {; }}$ 
where a, b, c, d and e are the respective slopes for the independent variables in the regression model. Negative slope values for egg size indicate the operation of an allocation trade-off between number of eggs and egg size.

\section{Results}

\section{$\underline{\text { Population density and biomass }}$}

In the upstream locality, the density of vendace as indicated by CPUE increased strongly from 1991-1992 until 1998. Subsequently the population density decreased by $93 \%$ until 2000 (Fig. 2a). The biomass of vendace remained fairly constant between 1991 and 1998, due to the larger fish size in the first years. However, during the period 1998-2000, the biomass of vendace decreased by 95\% (Fig. 2c).

In the downstream locality, the density of vendace remained relatively low and fairly constant from the first observation of the species in 1993 until 2000 (Fig. 2b). Similarly, the biomass of vendace showed only minor fluctuations throughout the same period (Fig. 2d).

\section{Length attained at age}

In the upstream locality, the mean lengths of vendace in all age-classes $(1+$ to $3+)$ decreased substantially from 1991 to $1993 / 1995$, stabilizing on small sizes in later years (Fig. 2e).

In the downstream locality, the mean lengths of vendace in age groups $2+$ and $3+$ increased from 1993 to 1995 . It should be noted that fish of age groups $2+$ and $3+$ in 1993 were similar in length in the upstream and the downstream locality. From 1995, age 
groups $1+$ to $3+$ demonstrated a similar decrease in size as in the upstream locality, and the decrease continued through 2000 (Fig. 2f).

Linear regressions between density and length attained at age revealed no significant statistical relationships for any age (1-3) or locality (upstream and downstream) ( $p>0.45$ for all combinations).

\section{Somatic growth of different year classes}

In the upstream locality, the mean length of the individual cohorts 1988-1990 decreased with increasing age (Fig. 3a). As an example, the 1990 cohort had a mean length of 139 $\mathrm{mm}$ as $1+$ in 1991 , but decreased in length through ages $2+, 3+$ and $4+$, finally reaching $121 \mathrm{~mm}$ as $5+$ in 1995 . In the year classes from 1991 onwards, mean lengths stagnated at approx. 110-120 mm, showing that adult size dropped sharply during the invasion process.

In the downstream lake the growth rates of the different cohorts were faster than in the upstream lake and the vendace stagnated at 130-140 mm body length (Fig. 3b). Growth stagnation occurred at a length similar to the one observed in the upstream locality during the first years of the invasion (1991-1993).

\section{Asymptotic length and individual growth rate to asymptote}

The von Bertalanffy growth model was applied to data on length and age for each year of study. The asymptotic length of vendace was considerably smaller in the pioneer population in the upstream part of the Pasvik watercourse in $1991(154 \mathrm{~mm})$ than in the 
donor population in Lake Inari, Finland in $1990(194 \mathrm{~mm})$. In the upstream locality of the Pasvik watercourse, the asymptotic length decreased quickly from 1991 (154 mm) until 1995 (117 mm), and then more slowly until 2000 (108 mm) (fig. 4a).

In the downstream lake, the asymptotic length was reduced from $167 \mathrm{~mm}$ in 1995 to $131 \mathrm{~mm}$ in 2000 (fig. 4a), illustrating a similar, but delayed change.

The estimated parameter $K$ (growth rate to asymptote) of the von Bertalanffy's equation had its lowest values in the mother population in Lake Inari (0.005), and increased over the years during the establishment in both the upstream (up to 0.016) and downstream (up to 0.017 ) parts of the Pasvik watercourse (fig. $4 b$ ).

\section{$\underline{\text { Size and age at first maturation }}$}

In the upstream locality the length at first maturation (mean value of the three smallest mature individuals within each year) decreased from $130 \mathrm{~mm}$ in 1991 to $82 \mathrm{~mm}$ in 2000, and most of the reduction occurred until 1993 (fig. 5), (closely resembling the length at age curves, especially the 1+ fish, in fig. 2). In the downstream locality, a weak negative trend in length at first maturation was seen between 1993 and 2000 (from $102 \mathrm{~mm}$ to 94 $\mathrm{mm}$ ), but with a peak value of $120 \mathrm{~mm}$ in 1997 (fig. 5).

In both localities vendace matured at the age of 1 year, and most $1+$ fish $(>80 \%)$ were mature in all years. Furthermore, in both localities, and within years, there were no significant differences in the mean size or age of mature males and females ( $t$-tests, $p>0.05)$. 


\section{$\underline{\text { Reproduction }}$}

In the upstream lake, mean female gonad weight decreased from about 3 grams in 1991 to about 1 gram in 1995-1999, whereas the downstream lake showed intermediate values, i.e. 1-2 grams (Fig. 6a). Similarly, the mean individual fecundity of female vendace in the upstream lake decreased from about 5000 eggs in 1991 to 1300 eggs in 1999, with intermediate values (1500-2800 eggs) in the downstream lake (Fig. 6b). In the upstream lake the gonadosomatic index (GSI) showed peak values in 1991 (11.9\%) and in 1999 (11.8\%), with a lower value in 1995 (6.9\%). In the downstream lake GSI was also low in 1995 (7.9\%) but higher in 1998 (10.9\%), the values being similar to the upstream lake (Fig. 6c). Regarding egg size, there was no apparent trend in the mean values in the upstream lake from 1991 to 2000, but egg sizes were largest in 1999 (Fig. 6d). In the downstream lake, egg size showed a slight decrease from 1995 to 2000.

In the upstream lake in 1991, the number of eggs per gram fish (relative fecundity) was on average 194, in later years between 95 and 130. In the downstream lake vendace had on average 110 eggs per gram fish.

\section{Reproductive investment}

Regressions between ln-transformed reproductive parameters (gonad weight, number of eggs, mean biomass of eggs) and ln weight (pooled data from both localities) revealed that all parameters increased significantly with fish weight (gonad weight: $r^{2}=0.67$, $p<0.001$; no. of eggs per female: $r^{2}=0.39, p<0.001$; mean size of eggs: $r^{2}=0.21$ $p<0.001$ ) (Fig. 7a-7c). 
In the downstream lake the gonadosomatic index (GSI) increased significantly with the age of the fish $\left(r^{2}=0.37 p<0.001\right)$, but no such relationship was found in the upstream lake $\left(r^{2}=0.01 p=0.414\right)($ Fig. 8$)$.

\section{Weight-and density-dependent trade-off between egg numbers and egg mass}

As locality, i.e. upstream versus downstream lake, was a significant $(F=5.24, p=0.024)$ factor in the total GLM-model, we first analysed the data from the two localities separately, including the effect of weight (i.e. controlling for the effect of weight), and excluding the effect of fish density.

In both localities, within years, there were mainly negative correlations (indicating trade-offs) between egg numbers and egg biomass, but the correlations were significant only in two out of eight cases (Tab. 2). When data from all years were pooled, significant negative slopes were found in both localities $(p<0.01)$. Pooling all data from both localities increased the level of significance $(p<0.001)$ (Tab. 2).

When density was included in the model, the trade-off between egg numbers and egg biomass became more pronounced in both localities separately, and when data from both localities were pooled, the operation of an allocation trade-off was most evident (slope $=-0.796, p<0.001)($ Tab. 2). 


\section{Discussion}

A gradual downstream invasion of vendace into the Pasvik watercourse has occurred in the 1990s, after introduction to the headwaters (Lake Inari) around 1960 (Mutenia and Salonen 1994). The invasion constitutes a large-scale field experiment (although from an unwanted invader) that has provided a rare opportunity to study the dynamic life history of an invading pioneer fish population through its establishment phase. Due to the plasticity in life histories of fish (Stearns 1992, Wootton 1998), the taxon is particularly suitable for studying responses to changes in external (environmental) and internal (e.g. abundance) conditions. The life history traits of vendace were followed in two localities (separated by 50 kilometers) through a range of different densities during a 10-year period.

Although vendace is specialised in terms of diet and habitat choice (Svärdson 1966, Svärdson 1976), it may vary substantially in life history parameters such as growth rate, age and size at maturity, individual fecundity, reproductive effort, and number of spawnings (Sarvala et al. 1992, Sandlund 1992, Sarvala and Helminen 1995). Vendace does not undergo ontogenetic niche shifts (Svärdson 1976, Sandlund 1992), and it may be vulnerable to impacts on food resources from its own population development (c.f. Hamrin and Persson 1986). Therefore, vendace may show interesting patterns of density dependent responses in life history, e.g. during colonization of new environments.

The population density of vendace in the upstream locality doubled between 1991 and 1998. During the same period the biomass of the fish remained fairly constant, due to decreasing individual size. There was a substantial reduction in length attained at age, a 
negative trend in intra-cohort mean length of the 1988-1990 year-classes and strongly reduced asymptotic length (1991-1995) (fig. 2-4). This decreasing individual size indicates a strong selective mortality that removed the largest fish within the first pioneer cohorts. Thus, the population seem to have been close to, or even surpassing, habitat carrying capacity. This is supported by a number of additional observations. The vendace upstream had very low stomach contents (Bøhn and Amundsen 2001), and the amount of edible zooplankton was substantially reduced in the upstream locality compared to downstream (Bøhn and Amundsen 1998, 2001). Finally, the native pelagic whitefish population in the upstream locality showed an interactive segregation, shifting from a diet of zooplankton to zoobenthos due to asymmetrical competition with vendace (Bøhn and Amundsen 2001). We therefore interpret the 93\% reduction in population density of vendace in the upstream locality between 1998 and 2000 as caused by resource depletion. This development is another example of the "boom and bust" phenomenon, which is fairly common among introduced species during establishment (Simpson 1984, Williamson and Brown 1986, Williamson 1996). Interestingly, none of the previously described examples of boom and bust developments in invader populations seem to have resulted in the invader disappearing completely from the locality (Williamson 1996). Thus, we would expect the vendace population in the upstream locality to establish a pattern of cyclic variation in abundance as commonly observed for this species in other systems (Hamrin and Persson 1986, Sandlund et al. 1991, Helminen et al. 1993).

In the downstream locality, vendace population density remained low throughout the study period (1993-2000). Even so, a reduction in length attained at age and asymptotic length, similar to the observations upstream, was evident from 1995 to 2000. 
This may suggest that the downstream population was facing resource limitation at a much lower density and biomass than the upstream population. However, the growth stagnation at a smaller size may also reflect a pioneer strategy of the invader in the new locality. In the pioneer-phase of establishment in a new environment, allocation of resources into early reproduction with high fecundity could be expected, trading off growth.

As both resource limitation (i.e. density dependence) and a pioneer strategy would lead to low growth rates, the interpretation of causes and effects may become blurred. A closer examination of the results in the upstream locality reveals that the negative trend in length at age ended 3-5 years before the population reached maximum density (fig. 2). Moreover, there were no statistically significant relationships (linear regressions) between length at age and population density. In addition, the growth parameters showed that the breakdown of the population after 1998 did not result in any immediate effect on growth in 1999-2000. A density decline in excess of 90\% (1998-2000 upstream) should plausibly result in competitive release and higher growth rates. It did not, even though the exploited resource consists mainly of crustacean zooplankton with short generation times, which should likely have been able to recover within the 2-year period after the crash of the vendace population. The lack of an expected competitive release supports the argument that density dependence is not the only mechanism acting here.

In comparison to vendace populations from southern Norway and Finland, the invading vendace in Pasvik show interesting differences in reproductive strategy. The gonadosomatic index (GSI) indicates that the reproductive investment was much lower in the Pasvik localities (mean 9.2 and $9.6 \%$ in the upstream and downstream lakes, 
respectively) compared to other populations of vendace in Finland and Norway (Lahti 1991, Lahti and Muje 1991, Sandlund 1992). In lakes Mjøsa and Osensjøen, vendace had a GSI of 25-29\%, produced 7000-11000 eggs per individual, and the age at first maturation was 2 - 5 years (Sandlund 1992). The low GSI values in Pasvik probably reflect energetic limitations due to restricted food resources in a sub-arctic climate, and the young age and small size of mature fish. In spite of the lower GSI, however, the small-sized fish in Pasvik produce two to three times more eggs per gram fish than the large sized fish in the southern Norwegian populations (110-143 vs. 53-60). In a situation when the vendace is invading a new environment, this very high relative fecundity, combined with early maturation (as 1 year old), may be seen as a successful achievement of an effective pioneer strategy.

In Pasvik, the gonadosomatic index (GSI) was positively correlated to the age of the fish in the downstream, but not in the upstream locality, indicating a lack of both growth potential and reproductive investment in older fish in the upstream locality. A slight increase in GSI values subsequent to the crash of the upstream population in 1998 indicates that more resources became available, and that these resources were allocated into reproductive investment rather than to somatic growth.

How a species, in practice, manages to adopt a pioneer strategy in a new environment is somewhat puzzling. Nevertheless, it makes sense in a life history theory context. Fitness in terms of lifetime production of offspring is maximised when sexual maturation is attained at an optimal age and size (Schaffer and Mettler 1974). This optimum is determined as a cost-benefit balance of maturation at different ages and sizes along a species-specific reaction norm (Stearns and Koella 1986, Stearns 1992). Late 
maturation results in higher individual fecundity and improved offspring survival, but also increased juvenile (pre-maturation) mortality. During population growth, life history theory predicts early maturation due to the power of shorter generation time during exponential growth (Lewontin 1965, Hamilton 1966). Also, within any age and size at maturation, there will be an expected trade-off between number and size of the offspring. At low resource levels a few, but large offspring are favoured (Stearns 1992, Reznick and Yang 1993, Hendry et al. 2001). In contrast, we found that high density (i.e. intraspecific competition) of vendace was accompanied by many small offspring. Also, the trade-off between egg numbers and egg size showed a priority on the number of offspring, in both localities. In the upstream locality, the number of eggs increased at the expense of egg size with increasing population density, indicating that cost of reproduction becomes more pronounced at high population densities. These observations support the pioneer strategy hypothesis, as also found in other taxa, e.g., plants, where species with many small offspring are the most successful invaders (Rejmanek 1999, Richardson et al. 2000).

Under unfavourable conditions (growth suppression) organisms should adjust age at maturity to maximize fitness (Stearns and Koella 1986). Growth suppression generally leads to delayed maturation at small sizes (Wootton 1973, McKenzie et al. 1983, Gibbons et al. 1981). In some cases, however, growth suppression leads to earlier reproduction at a smaller size (Alm 1959). The vendace showed a sharp decline in size at first reproduction, but no change in age at first reproduction (there were no significant differences within localities and years in mean size and age of mature females and males), supporting the notion that survival in relation to available food resources is size- rather 
than age-dependent (Hamrin and Persson 1986, Persson 1988). This also indicates that the range of age at first reproduction is restricted. In this sub-arctic watercourse vendace may hardly manage to reproduce at age $0+$. Reproduction at this age is mainly known from warmer and more productive regions (Svärdson 1966, Sarvala et al. 1992). The minimum observed size at maturity in Pasvik (80mm / 4 grams for males and $82 \mathrm{~mm} / 4$ grams for females), is probably the lower threshold of reproduction (cf. Wilbur and Collins 1973, Rowe et al. 1994, Day and Rowe 2002) for vendace in this system, or even in general for the species.

Predation may also play a role for the life history of the prey (Roff 2002). The impact of predation from piscivorous fish is usually larger on small prey, i.e., predation mortality is more pronounced in juvenile stages (Hambright et al. 1991, Persson et al. 1996, Næsje et al. 1998, Bøhn et al. 2002), and may result in rapid growth and delayed maturation in the prey population if there is an upper size-refuge. However, the vendace in Pasvik cannot outgrow its predators (Bøhn et al. 2002). Therefore the strategy of rapid growth through a predation window may not be successful in this particular predation regime.

The life-history strategy of a species is an important contributing factor determining the success of an invader. But successful invaders have a high diversity in life-history traits, as seen e.g. in birds (Lockwood 1999) and plants (Daehler 1998, Richardson et al. 2000). Thus, information about the biological characteristics and demographic strategies often appear insufficient to allow prediction of successful or failing invaders (Stauffer 1984, Arthington and Mitchell 1986). Rosecchi et al. (2001) argued that invasive vigour stems from the ability to tolerate environmental changes 
through phenotypic plasticity, rather than from particular life-history features pre-adapted to invasion. We argue further that phenotypic plasticity is not restricted to physical tolerance, as our study demonstrates that phenotypic plasticity acts directly on life history traits.

The invasion of vendace was characterized by several factors that seem to determine the successful establishment of invaders (c.f. Elton 1958, Pimm 1991, Lodge 1993, Williamson 1996, Sandlund et al. 1999). As an invader, vendace display a rapid life history (r-selected traits) and great phenotypic variability (rather than genetic variability). Furthermore, there was probably a significant propagule pressure from the headwaters (Lake Inari) through the 1980s. Important characteristics of the Pasvik watercourse also seem to have favoured the invasion. Humans have modified the watercourse from river to lake characteristics, favouring lacustrine species like vendace. Further, there is a low diversity and density of predators in the pelagic habitat (Bøhn et al. 2002), and the ecological saturation of sub-arctic ecosystems is generally low. Still we would expect that the trophic specialist vendace would face considerable competitive resistance from other zooplanktivorous fish. The native zooplanktivorous whitefish, however, has been documented to be the inferior competitor (Bøhn \& Amundsen 2001).

There are relatively few observations of invading trophic specialists as opposed to trophic generalists, albeit theory predicts the substitution of generalists by specialists during the process of diversification (Rosenzweig and Ziv 1999). The lower probability of success for monophagous as compared to polyphagous species may simply be explained by the lack of empirical data (Ebenhard 1988). The impact on native ecosystems seems in general to be much stronger from invading generalists (Ebenhard 
1988). In Pasvik, the invading vendace is a trophic specialist, competitively superior to the pelagic morph of the less specialized native whitefish with a similar niche (Bøhn and Amundsen 2001). The vendace has changed the prey zooplankton community, with cascading effects on primary production (Bøhn and Amundsen 1998). It has also adopted the role as the most important prey for pelagic piscivorous predators (Bøhn et al. 2002). The role of vendace as a dominant species in the pelagic food web, combined with a potential cyclic variation in abundance, may destabilize the aquatic ecosystem in the future.

In conclusion, the vendace in Pasvik demonstrates a highly plastic response in life history during the period of establishment. Negative density dependent responses on growth and fecundity patterns operate, but we argue that the vendace also display a pioneer strategy aiming to allocate resources into early reproduction at the expense of growth, with a priority on the number of eggs at the expense of egg size. Further, the invasive ability of vendace appears to result from a combination of high fecundity and strong competitive ability in a disturbed environment. Selective mortality on large and old individuals has caused a demographic change and a more rapid life history.

In perspective, this study illustrates that during invasions, ecological interactions may act strongly on life history traits in a population. A pioneer population in a new environment drive the development towards a new life history pattern. That's providing conditions for potential evolutionary change. 


\section{Acknowledgements}

Thanks to Malcolm Elliot for valuable comments on the manuscript and to Morten Johansen for statistical advice. Thanks also to Frode Staldvik, Laina Dalsbø, Jan Evjen, Elleke Wartena, Bjørn Hermansen, Vegard Steiro Amundsen, Hallvard Jensen, Ingrid Jensvoll and Karl Øystein Gjelland for help during field and laboratory work. Financial support was given by the Norwegian Research Council under the program 'Biological Diversity - Dynamics, Threats and Management', the Directorate for Nature Management and the Governor of Finnmark County. 


\section{References}

Alm, G. 1959. Connection between maturity, size and age in fishes. - Inst. Fresh. Res.

Drott. 40: 5-145.

Amundsen, P.-A., Staldvik, F. J., Reshetnikov, Y. S., Kashulin, N., Lukin, A., Bøhn, T., Sandlund, O. T. and Popova, O. A. 1999. Invasion of vendace Coregonus albula in a subarctic watercourse. - Biol. Conserv. 88: 405-413.

Arthington, A. H. and Mitchell, D. S. 1986. Aquatic invading species. - In: Groves, R. H. and Burdon, J. J. (eds.), Ecology of Biological Invasions. Springer, pp. 34-53.

Bøhn, T. and Amundsen, P.-A. 1998. Effects of invading vendace (Coregonus albula L.) on species composition and body size in two zooplankton communities of the Pasvik River System, northern Norway. - J. Plankton Res. 20: 243-256.

Bøhn, T. and Amundsen, P.-A. 2001. The competitive edge of an invading specialist. Ecology 82: 2150-2163.

Bøhn, T., Amundsen, P.-A., Popova, O. A., Reshetnikov, Y. S. and Staldvik, F. J. 2002. Predator avoidance of coregonids: habitat choice explained by size-related prey vulnerability? - Arch. Hydrobiol. 57: 183-197.

Charlesworth, B. 1994. Evolution in size-structured populations. - Cambridge University Press. 
Cohen, A. N. and Carlton, J. T. 1998. Accelerating invasion rate in a highly invaded estuary. - Science 279: 555-558.

Daehler, C. C. 1998. The taxonomic distribution of invasive angiosperm plants: ecological insights and comparison to agricultural weeds. - Biol. Conserv. 2: 167-180.

Day, T. and Rowe, L. 2002. Developmental thresholds and the evolution of reaction norms for age and size at life-history transitions. - Am. Nat. 159: 338-350.

Diamond, J. M. 1985. Introductions, extinctions, exterminations, and invasions. - In: Case, T. J. and Diamond, J. M. (eds.), Community Ecology. Harper \& Row, pp. 65-79.

Ebenhard, T. 1988. Introduced birds and mammals and their ecological effects. - Swedish Wildlife Research 13: 1-107.

Elton, C. S. 1958. The ecology of invasion by animals and plants. - John Wiley.

Forseth T., Halvorsen G.A., Ugedal O., Fleming I., Schartau A.K., Nøst T., Hartvigsen R., Raddum G., Mooij W. \& Kleiven E. 1997. Biologisk status i kalka innsjøer NINA Oppdragsmelding 508, 1-52 (in Norwegian with English abstract).

Gibbons, J. W., Semlitsch, R. D., Greene, J. L. and Schubauer, J. P. 1981. Variation in age and size at maturity of the slider turtle (Pseudemys scripta). - Am. Nat. 117: 841-845.

Glowka L., Burhenne-Guilmin F. \& Synge H. 1994. A guide to the Convention on Biological Diversity. IUCN, Gland \& Cambridge. 
Hambright, K. D., Drenner, R. W., McComas, S. R. and Hairston, N. G. 1991. Gape limited piscivores, planktivore size refuges, and the trophic cascade hypothesis. - Arch. Hydrobiol. 121: 389-404.

Hamilton, W. D. 1966. The moulding of early senescence by natural selection. - J. Theor. Biol. 12: 12-45.

Hamrin, S. F. and Persson, L. 1986. Asymmetrical competition between age classes as a factor causing population oscillations in an obligate planktivorous fish species. - Oikos 47: $223-232$.

Helminen, H., Auvinen, H., Hirvonen, A., Sarvala, J. and Toivonen, J. 1993. The yearclass fluctuations of vendace (Coregonus albula) in Lake Pyhäjärvi, Southwest Finland, during 1971-90. - Can. J. Fish Aquat. Sci. 50: 925-931.

Hendry, A. P., Day, T. and Cooper, A. B. 2001. Optimal size and number of propagules: Allowance for discrete stages and effects of maternal size on reproductive output and offspring fitness. - Am. Nat. 157: 387-407.

Hendry, A. P., Wenburg, J. K., Bentzen, P., Volk, E. C. and Quinn, T. P. 2000. Rapid evolution of reproductive isolation in the wild: Evidence from introduced salmon. Science 290: 516-518.

Lahti, E. 1991. The energy content and chemical-composition of eggs, muscle and liver in winter spawning vendace (Coregonus albula L.) before spawning. - Arch. Hydrobiol. 122: 373-379. 
Lahti, E. and Muje, P. 1991. Egg quality and female condition in vendace (Coregonus albula $\mathrm{L}$ ) before and during spawning. - Hydrobiologia 209: 175-182.

Langeland A. 1993. Pollution impact on freshwater communities in the border region between Russia and Norway. II. Baseline study 1990-1992. Norwegian Institute for Nature Research. Scientific report 44: 1-53.

Lewontin, R. C. 1965. Selection for colonizing ability. - In: Baker, H. G. and Stebbins, G. L. (eds.), The Genetics of Colonizing Species. Academic Press, pp. 77-94.

Lockwood, J. L. 1999. Using taxonomy to predict success among introduced avifauna: relative importance of transport and establishment. - Conserv. Biol. 13: 560-567.

Lodge, D. M. 1993. Biological invasions: Lessons for ecology. - Trends Ecol. Evol. 8: $133-137$.

McKenzie, W. D., Crews, D., Kallman, K. D., Policansky, D. and Sohn, J. J. 1983. Age, weight and the genetics of sexual-maturation in the platyfish, Xiphophorus maculatus. Copeia 3: 770-774.

Mills, E. L. and Eloranta, A. 1985. Reproductive strategies in the stone loach Neomacheilus barbatulus. - Oikos 44: 341-349.

Mills, E. L., Leach, J. H., Carlton, J. T. and Secor, C. L. 1993. Exotic species in the Great Lakes: a history of biotic crises and anthropogenic introductions. - J. Gt. Lakes Res. 19: $1-54$ 
Mooney, H. A. and Hobbs, R. J. 2000. Invasive species in a changing world. - Island Press.

Moyle, P. 1999. Effects of invading species on freshwater and estuarine ecosystems. - In:

Sandlund, O. T., Schei, P. J. and Viken, Å. (eds.), Invasive Species and Biodiversity Management. Kluver Academic Publishers, pp. 177-194.

Mutenia, A. and Salonen, E. 1992. The vendace (Coregonus albula L.), a new species in the fish community and fisheries of Lake Inari. - Arch. Hydrobiol. 39: 797-805.

Mutenia, A. and Salonen, E. 1994. Rehabilitation of the fisheries of Lake Inari, northern Finland. - In: Cowx, I. G. (ed.), Rehabilitation of freshwater fisheries. Fishing News Books, pp. 280-288.

Næsje, T. F., Jonsson, B. and Sandlund, O. T. 1986a. Drift of cisco and whitefish in a Norwegian river. - Trans. Am. Fish. Soc. 15: 309-314.

Næsje, T. F., Sandlund, O. T. and Jonsson, B. 1986b. Habitat use and growth of age-0 whitefish, Coregonus lavaretus, and cisco, C. albula. - Environ. Biol. Fishes 15: 309-314.

Næsje, T. F., Sandlund, O. T. and Saksgård, R. 1998. Selective predation of piscivorous brown trout (Salmo trutta L.) on polymorphic whitefish (Coregonus lavaretus L.). Archive für Hydrobiologie Spec. Issues Advanc. Limnol. 50: 283-294.

Persson, L. 1988. Asymmetries in competitive interactions. - In: Ebenman, B. and Persson, L. (eds.), Size-structured Populations - Ecology and Evolution. Springer-Verlag, pp. 203-218. 
Persson, L., Andersson, J., Wahlstrøm, E. and Ekløv, P. 1996. Size-specific interactions in lake systems: predator gape limitation and prey growth rate and mortality. - Ecology 77: $900-911$.

Pimm, S. L. 1991. The balance of nature? - The University of Chicago Press.

Rask M., Appelberg M., Hesthagen T., Tammi J., Beier U. \& Lappalainen A. 2000. Fish status survey of Nordic lakes - species composition, distribution, effects of environmental changes. TemaNord 2000 508: 1-58.

Rejmanek, M. 1999. Invasive plant species and invasible ecosystems. - In: Sandlund, O. T., Schei, P. J. and Viken, Å. (eds.), Invasive species and biodiversity management. Kluwer Academic Publishers, pp. 79-102.

Reznick, D. N., Shaw, F. H., Rodd, F. H. and Shaw, R. G. 1997. Evaluation of the rate of evolution in natural populations of guppies (Poecilia reticulata). - Science 275: 19341937.

Reznick, D. N. and Yang, A. P. 1993. The influence of fluctuating resource availability on female life histories in Poecilia reticulata: patterns of allocation and plasticity. Ecology 74: 2011-2019.

Richardson, D. M., Alsopp, N., D'Antonio, C. M., Milton, S. J. and Rejmanek, M. 2000. Plant invasions - the role of mutualisms. - Biol. Rev. 75: 65-93.

Roff, D. A. 1984. The evolution of life-history parameters in Teleosts. - Can. J. Fish Aquat. Sci. 41: 989-1000. 
Roff, D. A. 1992. The evolution of life histories: data and analysis. - Chapman \& Hall.

Roff, D. A. 2002. Life history evolution. - Sinauer Associates, Sunderland.

Rosecchi, E., Thomas, F. and Crivelli, A. J. 2001. Can life-history traits predict the fate of introduced species? A case study on two cyprinid fish in southern France. - Freshw. Biol. 46: $845-853$.

Rosenzweig, M. L. and Ziv, Y. 1999. The echo pattern of species diversity: pattern and process. - Ecography 22: 614-628.

Rowe, L., Ludwig, D. and Schluter, D. 1994. Time, condition, and the seasonal decline of avian clutch size. - Am. Nat. 143: 698-772.

Sandlund O.T. 1992. Differences in the ecology of two vendace populations separated in 1895. Nordic Journal of Freshwater Research 67: 52-60.

Sandlund, O. T., Jonsson, B., Næsje, T. F. and Aass, P. 1991. Who's got the upper hand in intraspecific competition? - J. Fish Biol. 38: 873-885.

Sandlund, O. T., Schei, P. J. and Viken, Å. 1999. Invasive species and biodiversity management. - Kluwer Academic Publishers.

Sarvala, J. and Helminen, H. 1995. Significance of egg size variation in the year-class fluctuations of vendace (Coregonus albula). - Archive für Hydrobiologie Spec. Issues Advanc. Limnol. 46: 187-194. 
Sarvala, J., Helminen, H. and Hirvonen, A. 1992. Fecundity of vendace (Coregonus albula) in relation to year-class variations in Lake Pyhäjärvi, SW Finland. - Polskie Archiwum Hydrobiologii 39: 341-349.

Schaffer, H. E. and Mettler, L. E. 1974. Teaching population fitness and adaptive surfaces in population and quantitative genetics. - Journal of Heredity 65: 189-192.

Simpson, D. A. 1984. A short history of the introduction and spread of Elodea Michx. in the British Isles. - Watsonia 15: 1-9.

Skurdal, J., Vøllestad, L. A. and Qenild, T. 1985. Comparison of scales and otoliths for age determination in whitefish Coregonus lavaretus. - Fish. Res. 3: 237-243.

Stauffer, J. R. 1984. Colonisation theory relative to introduced populations. - In:

Courtenay, W. R. and Stauffer, J. R. (eds.), Distribution, Biology and Management of Exotic Fishes. Johns Hopkins University Press, pp. 8-21.

Stearns, S. C. 1992. The Evolution of Life Histories. - Oxford University Press.

Stearns, S. C. and Koella, J. C. 1986. The evolution of phenotypic plasticity in life-history traits: predictions of reaction norms for age and size at maturity. - Evolution 40: 893-913.

Svärdson G. 1966. Siklöjans tillväxt och utbredningsgränser. Information, Søtvattenslaboratoriet, Drottningholm 4: 1-24. (in Swedish).

Svärdson, G. 1976. Interspecific population dominance in fish communities in Scandinavian lakes. - Institute of Freshwater Research Drottningholm 55: 144-171. 
Welcomme, R. L. 1992. A history of international introductions of inland aquatic species. - International council for the exploration of the Sea Marine Science Symposia 194: 3-14.

Wilbur, H. M. and Collins, J. P. 1973. Ecological aspects of amphibian metamorhosis. Science 182: 1305-1314.

Williamson, M. 1996. Biological invasions. - Chapman \& Hall.

Williamson, M. 1999. Invasions. - Ecography 22: 5-12.

Williamson, M. H. and Brown, K. C. 1986. The analysis and modeling of British invasions. - Philos. Trans. R. Soc. Lond. B Biol. Sci. 314: 505-522.

Wootton, R. J. 1973. Effect of size of food ration on egg-production in female 3-spine stickleback, Gasterosteus aculeatus L. - J. Fish Biol. 5: 89-96.

Wootton, R. J. 1998. Ecology of Teleost Fishes. - Kluwer Academic Publishers. 
Table 1. Catches of vendace, separated in the three main habitats, in the upstream and downstream locality in the Pasvik watercourse in the period from 1991-2000.

\begin{tabular}{lllllllllll}
\hline Locality & Habitat & 1991 & 1992 & 1993 & 1995 & 1997 & 1998 & 1999 & 2000 & Sum \\
\hline Upstream & Pelagic & 67 & 48 & 599 & 270 & 199 & 394 & 166 & 304 & 2047 \\
& Profundal & 2 & 3 & 26 & 8 & 8 & 13 & $*$ ) & 14 & 74 \\
& Littoral & 0 & 0 & 19 & 2 & 22 & 22 & $*)$ & 11 & 76 \\
\hline Downstr. & Pelagic & 0 & 0 & 76 & 21 & 23 & 149 & 0 & 93 & 362 \\
& Profundal & 0 & 0 & 10 & 1 & 7 & 46 & $*)$ & 11 & 75 \\
& Littoral & 0 & 0 & 4 & 2 & 0 & 5 & $*)$ & 3 & 14 \\
\hline TOTAL & & 69 & 51 & 734 & 304 & 259 & 629 & 166 & 436 & 2648 \\
\hline
\end{tabular}

*) No sampling in benthic habitats 
Table 2. Correlations (values of slopes from the GLM-model, equation 3) between lntransformed values of egg numbers and egg size (dry weight biomass), correcting for (ln) fish weight, and density as indicated. NS $=$ not significant, $* *=p<0.01, * * *=p<0.001$. Negative slopes reflect trade-offs between egg numbers and egg size.

\begin{tabular}{|c|c|c|c|c|}
\hline Year & $\begin{array}{l}\text { Upstream } \\
\text { (slopes) }\end{array}$ & $\mathrm{n}=$ & $\begin{array}{l}\text { Downstream } \\
\text { (slopes) }\end{array}$ & $\mathrm{n}=$ \\
\hline 1991 & $-0.498 * *$ & 7 & & \\
\hline 1995 & $-0.314 \mathrm{NS}$ & 32 & $-0.317 \mathrm{NS}$ & 13 \\
\hline 1998 & $+0.060 \mathrm{NS}$ & 23 & $-0.683 * *$ & 19 \\
\hline 1999 & $-0.581 \mathrm{NS}$ & 25 & & \\
\hline 2000 & $-0.216 \mathrm{NS}$ & 11 & $-0.533 \mathrm{NS}$ & 13 \\
\hline All years & $-0.432 * *$ & 98 & $-0.659 * *$ & 45 \\
\hline All years both localities & \multicolumn{4}{|c|}{$-0.549 * * *(\mathrm{n}=139)$} \\
\hline $\begin{array}{l}\text { All years including density (upstream model) } \\
\left(\ln E g g_{\#}=-0.785 \ln E g G S I_{\mathrm{ze}}\right. \\
\left.+1.594 \ln \text { Weight }_{\text {fish }}-0.005 \text { Density }_{\text {fish }}\right) \\
r^{2}=0.55(F=36.02, p<0.001)\end{array}$ & $-0.785 * * *$ & 98 & & \\
\hline $\begin{array}{l}\text { All years including density (downstream model) } \\
\left(\ln E g g_{\#}=-0.721 \ln E g G S I_{\mathrm{ze}}\right. \\
\left.+1.235 \ln \text { Weight }_{\text {fish }}-0.001 \text { Density }_{\text {fish }}\right) \\
r^{2}=0.49(F=13.07, p<0.001)\end{array}$ & & & $-0.721 * *$ & 45 \\
\hline $\begin{array}{l}\text { All years both localities including density (total model) } \\
\left(\ln E g g_{\#}=-0.796 \ln E g G S I_{\mathrm{ze}}\right. \\
\left.+1.597 \ln \text { Weight }_{\text {fish }}-0.004 \text { Density }_{\text {fish }}\right) \\
r^{2}=0.56(F=57.40, p<0.001)\end{array}$ & \multicolumn{4}{|c|}{$-0.796 * * *(\mathrm{n}=139)$} \\
\hline
\end{tabular}




\section{Figure legends}

Figure 1. Map over the Pasvik watercourse. The arrow shows the upstream point of invasion. Hydropower dams are marked and arcs show the year of the first vendace observation.

Figure 2a) and b): Density (CPUE - number of fish per $100 \mathrm{~m}^{2}$ gillnet per 12 hours) of vendace in the upstream (1991-2000) and downstream lake (1992-2000).

c) and d): Relative biomass in the upstream (1991-2000) and downstream lake (19922000).

e) and f): Mean length attained at ages $1+, 2+$ and $3+$ for vendace from the upstream (1991-2000) and downstream lake (1993-2000).

Figure 3. Growth of different year-classes in the a) upstream (1988-1997) and b) downstream (1991-1998) locality.

Figure 4. Growth parameters, a) asymptotic length, and b) growth rate to asymptote, estimated from a modified von Bertalanffy growth model (see methods) in the upstream (1991 to 2000) and downstream (1993-2000) locality, and from the mother population in Lake Inari in 1990. Length at hatching was assumed to be $11 \mathrm{~mm}$.

Figure 5. Length at first maturation (mean value of the three smallest mature individuals within each year) in the upstream (1991-2000) and downstream (1993-2000) locality. 
Figure 6 . Fecundity parameters in different years: a) total gonad weight (wet weight), b) number of eggs, c) gonadosomatic index (GSI) and d) mean size (biomass) of individual eggs (dry weight) in the upstream (filled bars) and downstream (hatched bars) lakes. Error bars show S.E.

Figure 7. Linear regressions between $\ln$ weight and a) $\ln$ gonad weight (wet weight), b) $\ln$ number of eggs and c) mean size (biomass) of individual eggs (dry weight). Symbols ' 1 ' denote year $1991,{ }^{\prime} 5{ }^{\prime}=1995,{ }^{\prime} 8{ }^{\prime}=1998,{ }^{\prime} 9{ }^{\prime}=1999$ and ${ }^{\prime} 0{ }^{\prime}=2000$. Data from the upstream and downstream locality were pooled.

Figure 8. Linear regressions between gonadosomatic index $(G S I)$ and age in the upstream (symboled 'o'; solid line) and downstream locality (symboled ' $x$ '; dashed line). Data from all years were pooled. 


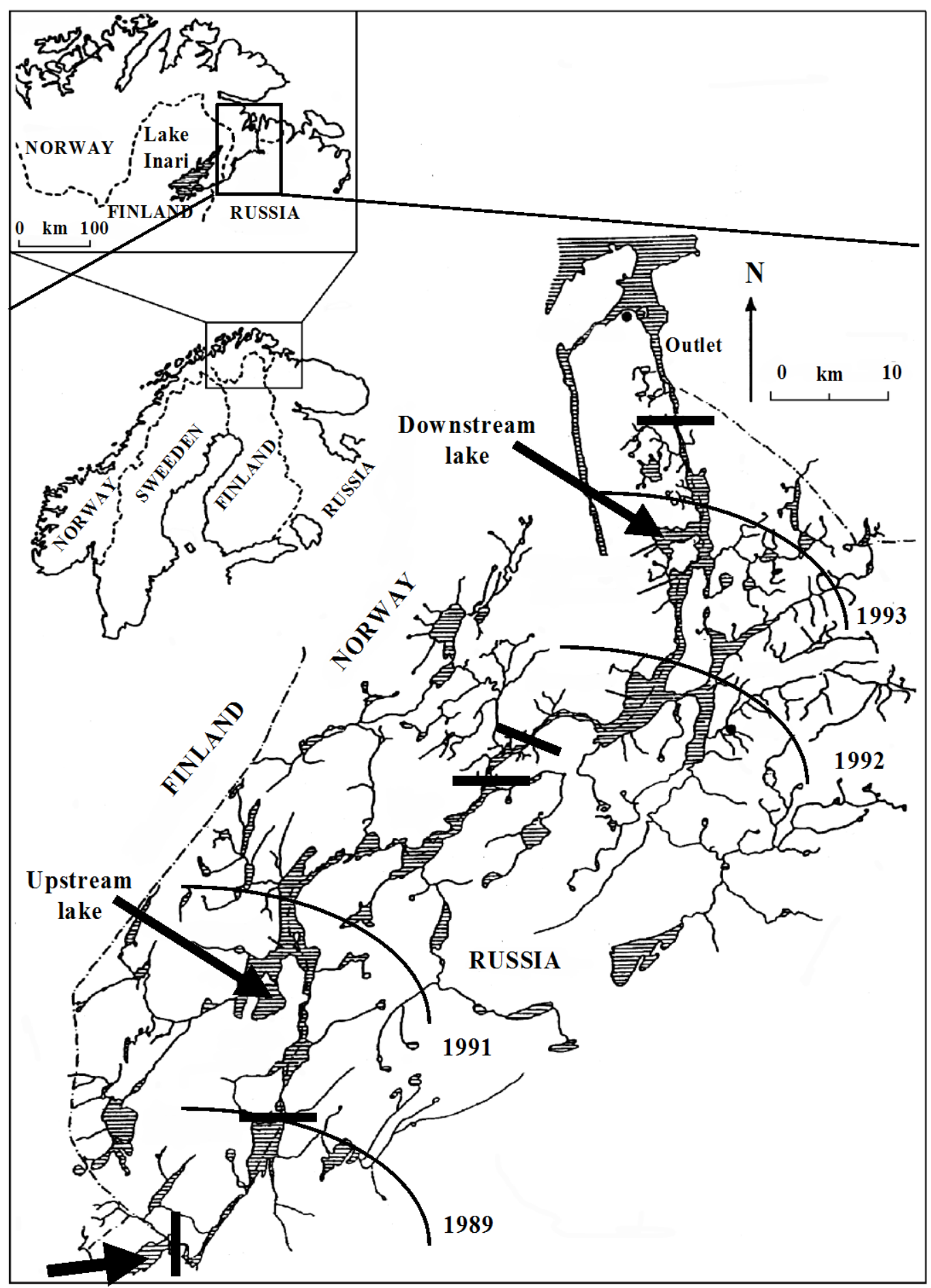

Fig. 1. 


\section{Upstream Downstream}
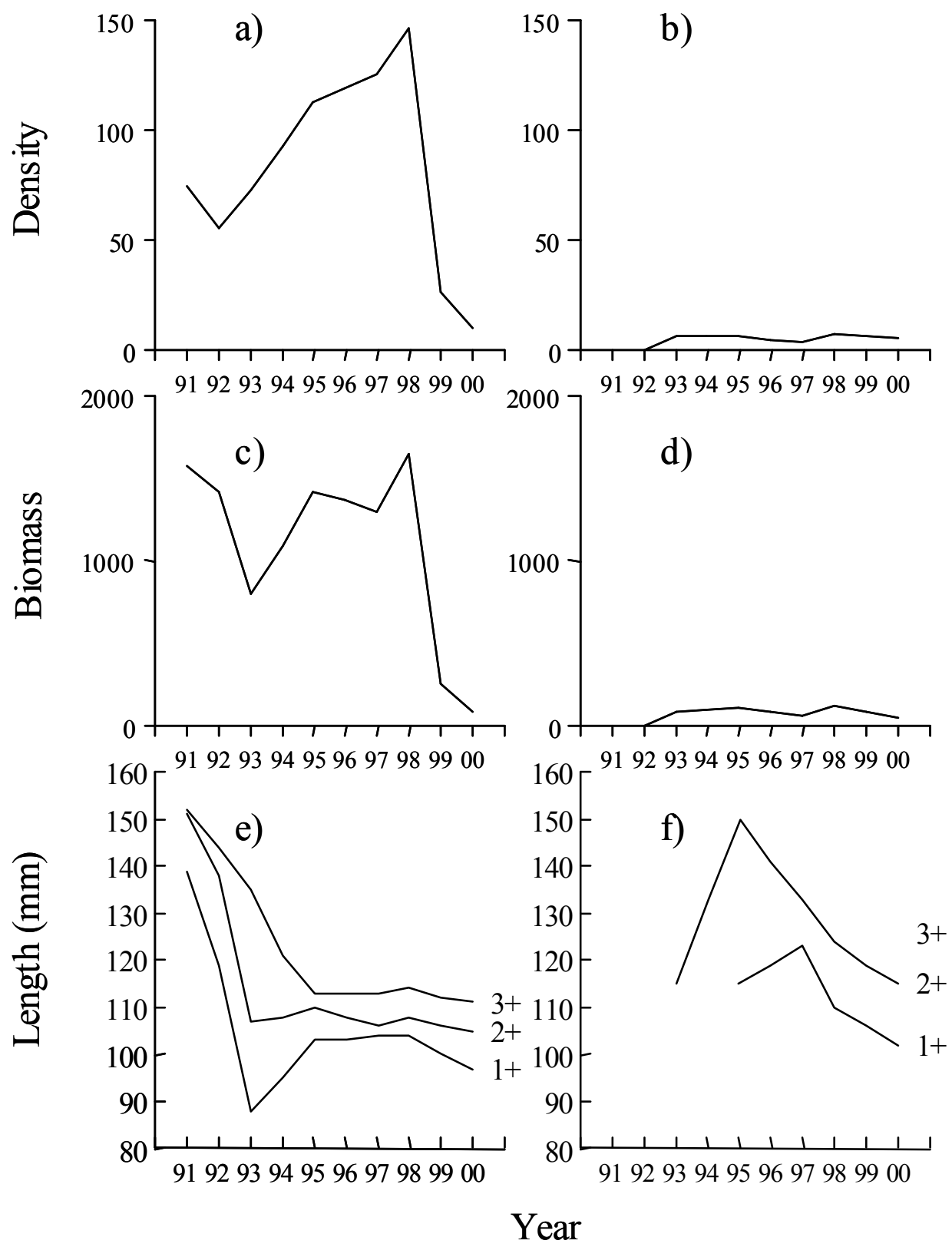

Fig. 2. 

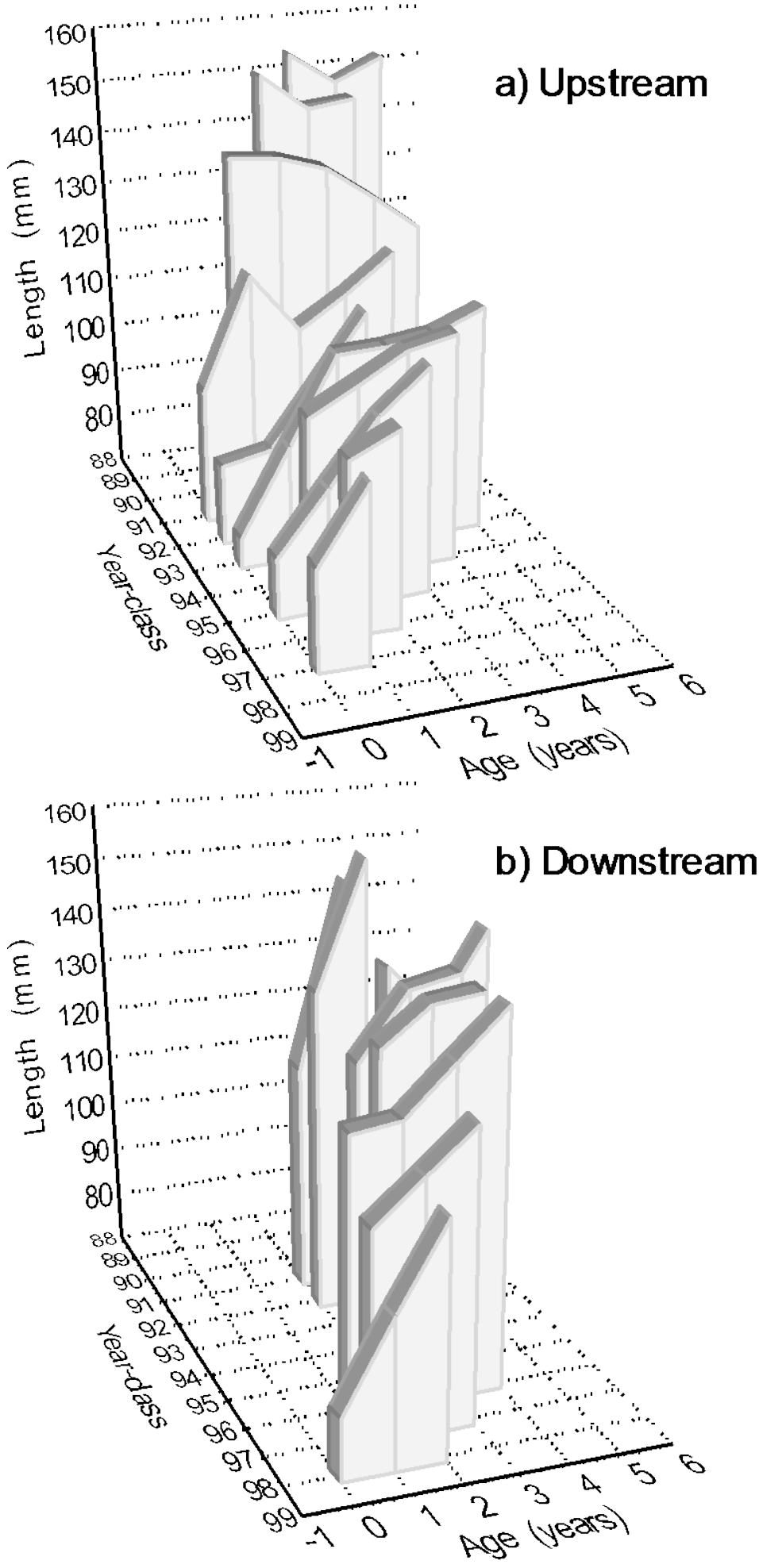

Fig. 3. 

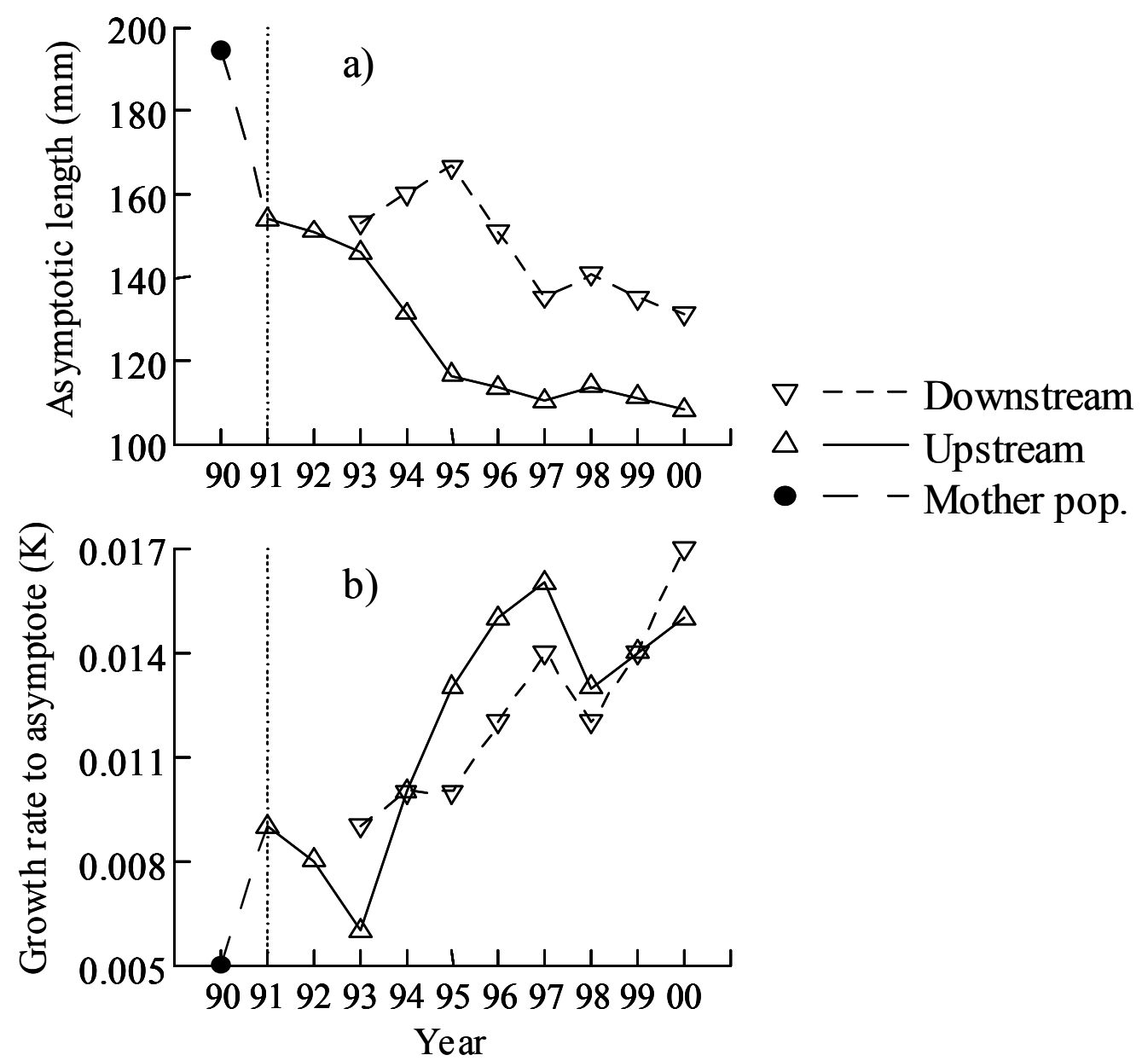

Fig. 4. 


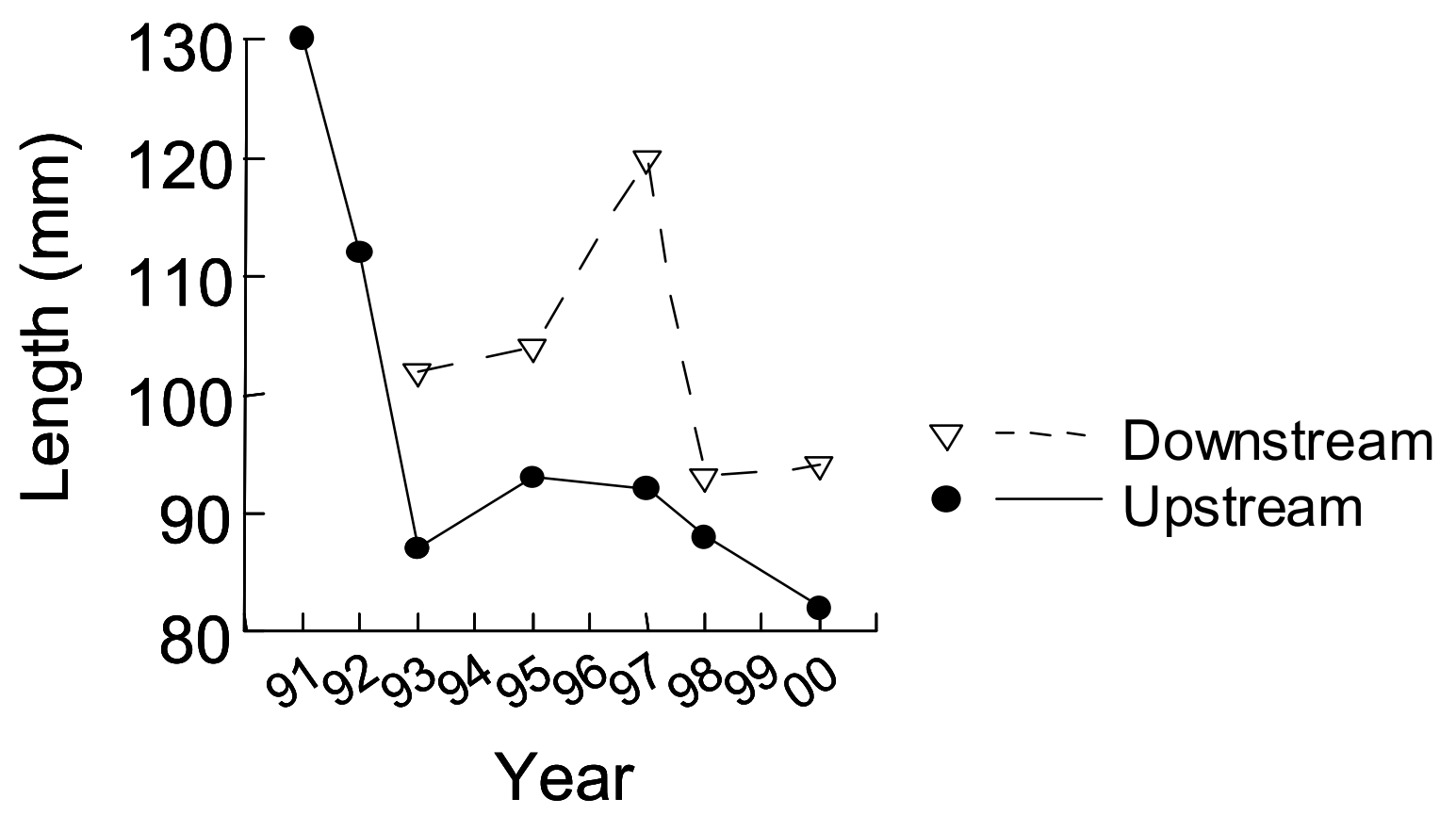

Fig. 5. 

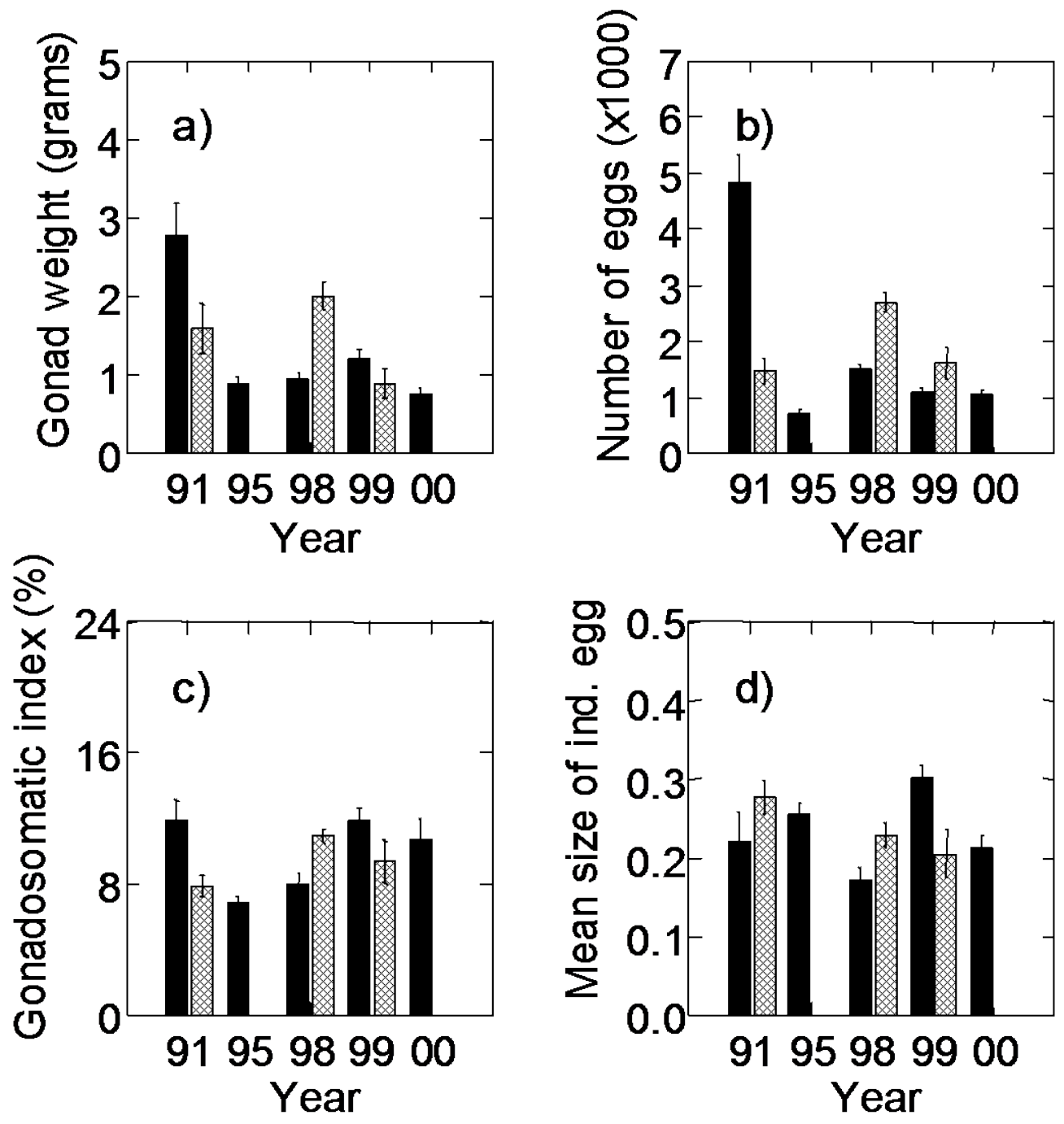

Fig. 6. 

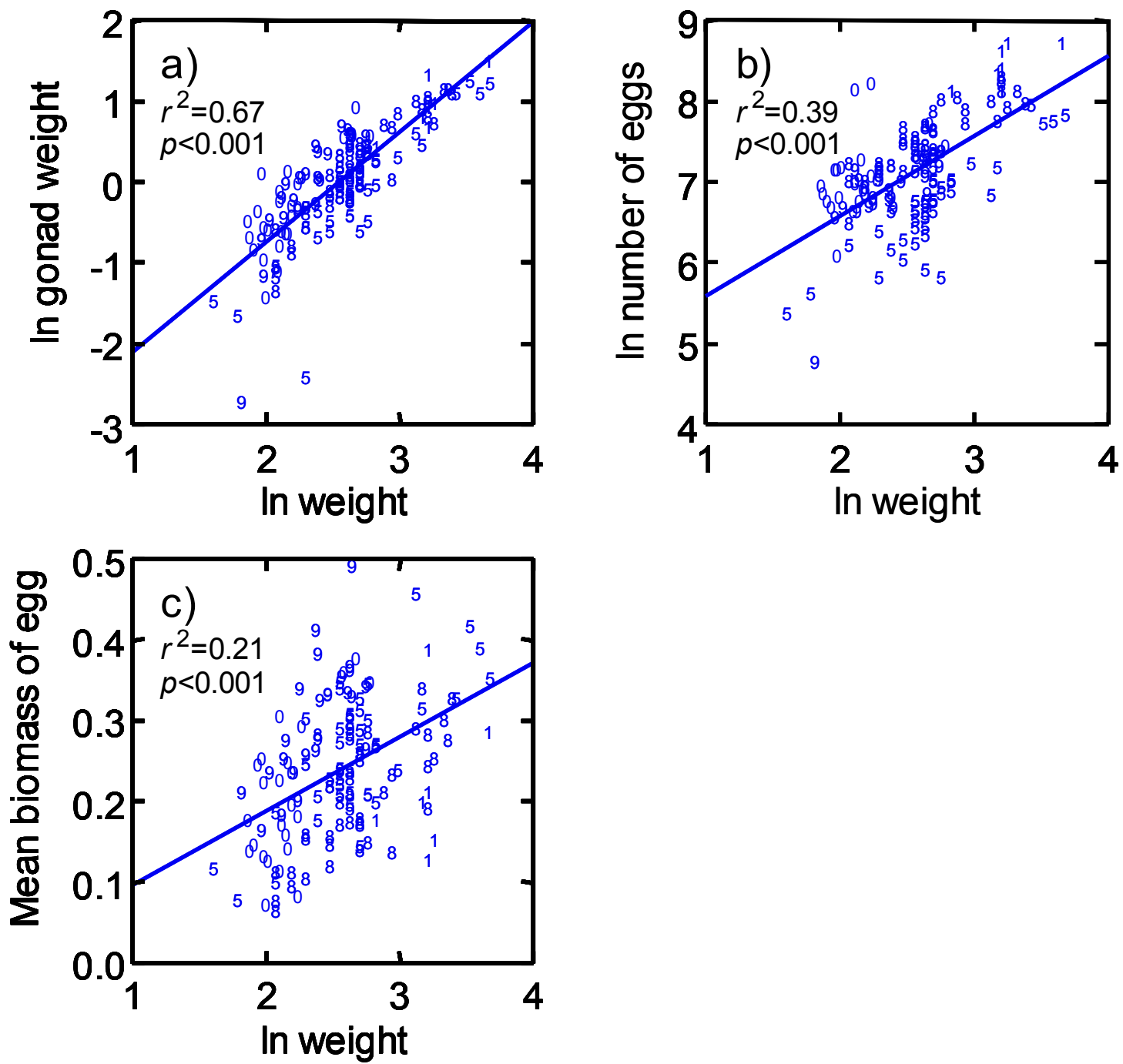

Fig. 7. 


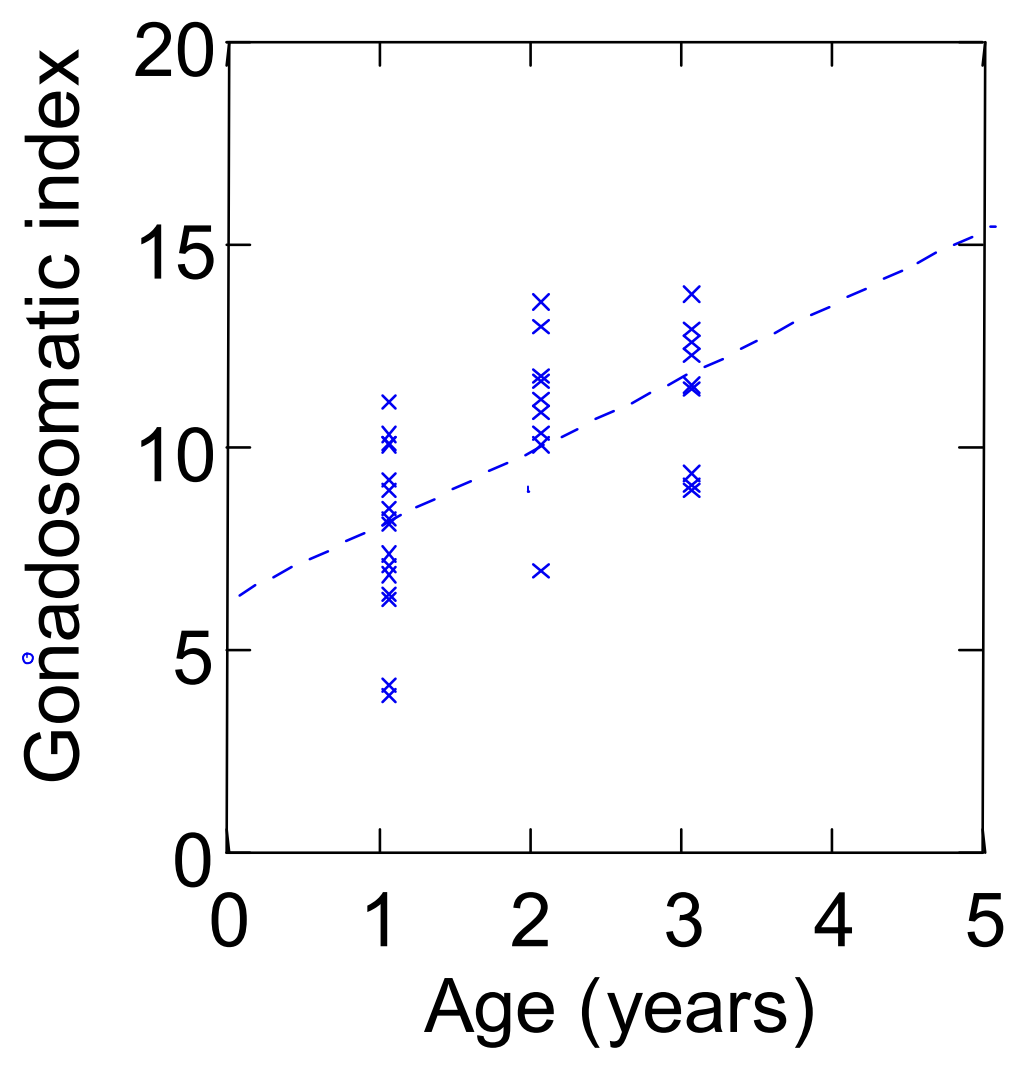

Fig. 8 . 